\title{
New optical filter employing miultirefiection mirror to provide design flexibility for WDMA
}

\author{
S. Vargas, C. Vázq̨uez
}

Dpto. Ingeniería Fífectrica, Electrónica y Automática, Aróa Tecnologia Lilectrónica, Univeisidad Carlos ItI, Av. Universidad 30, Legaués 28911, Malrid, Spain - Fax: 3416249430 - T-mail: cvazquez@ing.uc3m.cs

Abstract: An optical filter employing multireflection mirror within an amplified ring resonator is presented. The multireflection mirror allows bandpass frequency response tuning by changing the coupling factor of a coupler. The device can achieve higher crosstalk with lower gain values in comparison with previous optical flters with similar architecture. Easy to use expressions to simplify design process are derived.

\section{Introduction}

Single-hop architectures in multiwavelength networks use control channels to inform the destination node that a packet has been transmitted and to which channel to thine its receiver [1]. One optimum way is using sulscanier multiple access (SCMN) for the control channels. Key components to extract those headers are tuneable filters and routers, which can also be used in a self-routing lirequency Division Multiple Access (EDMA) topology [2]. Some optical filters previously reported are cascaded Mach-Zehnder (M7) demultiplexers [3], Amplified Ring Resonators (ARR) with a ISR limited by ring length [4]. Other devices aie based on ARR and Bragg Giatings (BC) to overcome FSK constraint [5]. In any of them tuning process is done by means of changing ring length.

In this paper an optical filter is presented. It is based on an $\Lambda \Lambda R$ and BG but it has an extia flexibility in the tuning process, which can be done in the conventional way or by clianging the coupling factor of a coupler. This coupling factor controls the multireflection mirior and allows low gain levels for optimum performance. Basic architecture along with analytical expressions to make easy the design and the tuning process are reported.

\section{l’unciple and Design Equations}

Optical filter reported here comprises an amplified ting resonator $(\Lambda \mathrm{RR})$ and a non-periodic bandpass fillter, which consist on a coupler and two equals BG, see Fig.1, which behaves as a multireflector inirrot. The architecture is similar to the device described in [5-6] but a general coupler replaces the $3 \mathrm{~dB}$ coupler of the non-poriodic band pass filter. The selection of the coupling factor controls the separation between selected chaninels. Output power at port 3 and port 4 is obtained from the following equations:

$$
\begin{aligned}
& P_{3}=(1-\gamma)^{1 / 2}\left\lfloor\sqrt{1-K} \cdot P_{1}+j \cdot \sqrt{K} \cdot P_{2 f}\right\rfloor \\
& P_{4 f}=(1-\gamma)^{1 / 2}\left\lfloor j \sqrt{K} \cdot P_{1}+\sqrt{1-K} \cdot P_{2 f}\right\rfloor \\
& P_{2 f}=\sqrt{G} \cdot z^{-1}\left\lfloor F t_{1} \cdot P_{4 f}+\sqrt{G} \cdot F r_{1} \cdot P_{2 b}\right\rfloor \\
& P_{2 b}=(1-\gamma)^{1 / 2} \cdot \sqrt{1-K} \cdot P_{4 b} \\
& P_{4 b}=z^{-1}\left\lfloor\sqrt{G} \cdot F t_{1} \cdot P_{2 b}+F r_{1} \cdot P_{4 f}\right\rfloor
\end{aligned}
$$

$\mathrm{Ft}_{1}$ and $\mathrm{Fr}_{1}$ are transmission and reflection transfer function of the multireflector mirror respectively.

From previous equations it can be derived that output power at port 3 is given by:

$$
\frac{P_{3}}{P_{1}^{3}}(z)=(1-\gamma)^{1 / 2}\left[\frac{A+B z^{-1}+C z^{-2}}{1+D z^{-1}+E z^{-2}}\right]
$$

Poles and zeros locations are obtained from $(6)$ and operating with them we oblain that the separation in frequency of the two nuxima that now appear is controlled by $\mathrm{Kb}$ througl the following expression:

$$
\Delta=\left(0.5-\frac{\phi}{\pi}\right)\left[\frac{n+c T\left(\alpha_{p}+\sqrt{k_{p}{ }^{2}+\alpha_{p}{ }^{2}}\right)}{c\left(\alpha_{p}+\sqrt{k_{p}{ }^{2}+\alpha_{p}{ }^{2}}\right)}\right]
$$

with $\phi$ for the poles equal to: 
$\phi=\operatorname{atan}\left[\frac{2 \sqrt{K_{b}-K_{b}{ }^{2}}}{1-2 K_{b}}\right]$

where $n$ is the refractive index, $c$ is light velocily, $\alpha_{p}$ and $k_{\mathrm{f}}$ alre loss and coupling coeflicient of Bragg grating respectively $[7]$.

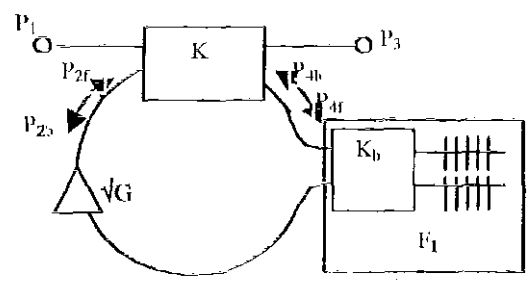

Figure. Filter schentatic

At ligg. 2.al and 2.1) it can be seen outpul power at port $3, \mathrm{P}_{3}$, and port 4 forwatd, $P_{46}$, with and withoul multireflection mirror. lis the list case, no multireflection mincor is considered, that can be accomplished using $\mathrm{K} / \mathrm{h}-0.5$ or using an isolator, The transfer function is equivalent to that repoited in [6] with a maximum at $B(\mathrm{j}$ central wavelongth. Fior $\mathrm{K}=0.1$, $(\mathrm{j}=1.3, \mathrm{~Kb}=0.55$ and $\mathrm{BG}$ i with a $99 \%$ reflectivity and a JWIIM of $0.14 \mathrm{fm}$ a crosstalk of $20 \mathrm{~dB}$ is obtained. Using the novel device, with no isolator, so $F$, behaves as a multireflection nitror, with the satme values of $(i, K b$ and $\mathrm{K}$, and the same $B(i$ and using Fe. (6), we can see that two ninimal separated

by $320 \mathrm{MIJ}$, appear. $\Lambda$ crosstalk of $35 \mathrm{~dB}$ in port $3, P_{3}$, is obtained, so we can have 20 dls crostalk with a lower gain value.

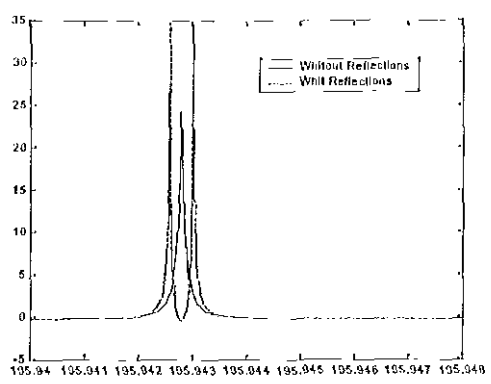

Figure 2a: Output power at port 3 , with and without multireflection mirror.

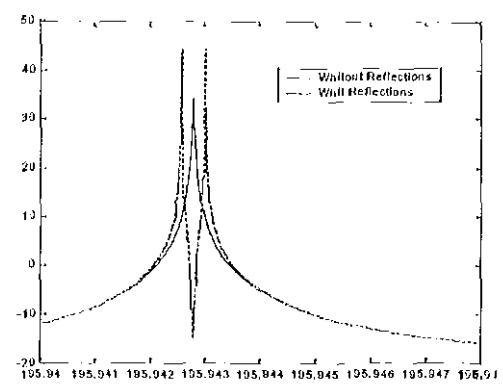

Figure 2b: Ontput power at port 4 forward with and without multireflection mirror.

\section{Conclusions}

A novel optical device employing an amplified ring rusonator and a inultireflecting mirror inside, is presented. Is founded its transfor function. Also simple expressions for the separation of the two maximums of this novel transfer function are developed. We have oltain separations of $320 \mathrm{MHz}$, for $\Delta \mathrm{K}_{b}=0.05$.

\section{Ackiowledgenents}

We wish to thank J. M. Sánchez ['ona and "Displays and Photonics Applications Group" at Carlos III University. This work wis suppoited by Spanish CICYT (I'IC-98-0397-C03-03) and a grant from lnternational Cooperation Spanish $A g e n c y$.

\section{References}

/1/ J.M. Senior, M.R. Handley, and M.s. Leeson. "Developments in Wavelength Division Multiple Aceess Networking". IEEL Communications Magazine, 28-36, December 1998.

/2/ S. Tsao, II. Tsilo and Y. I.es. "Design of Self-Routing Frequency Division Multiple Access (SR-lDM D) Network using and Optical Ring Filter with or without gelin als a Router". J. Lightwave Tech., $2168-2182.1995$.

/3/ D.J.G. Mestdagh. "Multiple Access Techniques for Jiber-(Optic Netwoks". Optical Fiber Technology, 2, 7-54, 1996.

/4/ A. Yariv. "Universal relations for coupling of optical power between microresonator and dielectric waveguides", Llectr. J.etters, 36, 321-322, 2000.

/5/ C. Vázques, J. F. Iterinández-Cill and M. Iópez-Amo. "Tunable Ring Resonator Filter for OFDM Transmission Systems". Microw. Opt. L,ett, 8, 321-323, 1995.

/6) C. Vizquez, S. Vargas, J. M. S. Pena; "Tesign ant Tolerunce Analysis of a Router with an Amplified Kesonator and Bragg (iratings", Applied Optics, Vol. 39, No. 12, April 2000

17/ IIarol M. Stoll, "Optimally Coupled, GaAs-Distributed Jragg Reflection Lasers", IEIII: Transactions on Circuits aind Systems, Vol. Cas-26, No. 12, 1)ec. 1979. 